\title{
A Case Demonstrating the Cardio-Vascular Interaction by a New Cardio-Ankle Vascular Index During the Treatment of Concentric Hypertrophy
}

\author{
Kazuhiro Shimizu a, b, c, Tsuyoshi Tabata ${ }^{\mathrm{b}}$, Hajime Kiyokawa ${ }^{\mathrm{a}}$, Yukihiro Morinaga ${ }^{\mathrm{b}}$, \\ Shuji Sato ${ }^{a}$, Hiroshi Mikamo ${ }^{\text {a }}$, Takahiro Nakagamia ${ }^{\mathrm{a}}$, Takuo Iiduka ${ }^{\mathrm{a}}$, \\ Kohji Shirai ${ }^{a}$, Mahito Noro ${ }^{\mathrm{a}}$
}

\begin{abstract}
A 42-year-old hypertensive woman came to our hospital suffering from shortness of breath. Her left ventricular mass index (LVMI) was increased, and a new arterial stiffness index, cardio-ankle vascular index (CAVI), was also elevated. By treating hypertension (HT), diabetes mellitus (DM) and obstructive sleep apnea (OSA), her left ventricular concentric hypertrophy was improved, accompanying with a decrease in CAVI. These observations suggested that arterial stiffness monitored with CAVI might be involved in cardiac hypertrophy. This cardio-vascular interaction could be demonstrated at the first time by monitoring CAVI, which is not affected by blood pressure (BP) at measuring time.
\end{abstract}

Keywords: Hypertension; Left ventricular mass index; Global longitudinal strain; Concentric hypertrophy; Cardio-ankle vascular index; Cardio-vascular interaction

\section{Introduction}

Left ventricular hypertrophy (LVH) associated with hypertension (HT) is very important as it indicates the beginning of heart failure [1]. LVH is caused by overwork of cardiac muscle and is also supposed to be affected by so-called afterload, which consists of vascular resistance. There are several indices of LVH. Ejection fraction (EF) is a popular index reflecting left ventricular (LV) function and heart failure with preserved ejection fraction (HFpEF) affecting approximately $50 \%$ of the

Manuscript submitted December 4, 2018, accepted December 12, 2018

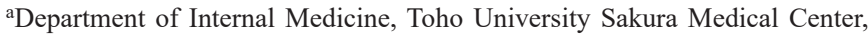
Chiba, Japan

${ }^{b}$ Department of Clinical Physiology, Toho University Sakura Medical Center, Chiba, Japan

${ }^{\mathrm{c} C}$ Corresponding Author: Kazuhiro Shimizu, Department of Internal Medicine,

Toho University Sakura Medical Center, Chiba, Japan.

Email: K432@sakura.med.toho-u.ac.jp

doi: https://doi.org/10.14740/cr812 patients with clinical heart failure [2]. Assessment of myocardial deformation using two-dimensional (2D) speckle-tracking echocardiography for the measurement of global longitudinal strain (GLS) has begun to be recognized as a sensitive and objective modality and may represent a useful tool for the HFpEF population [3, 4]. GLS analysis by speckle-tracking echocardiography has been proven to be a stronger predictor of patient outcome than left ventricular ejection fraction (LVEF) $[5,6]$. While peak systolic longitudinal LV strain is quantified in the three apical views using the 2D speckle-tracking method in a 17 -segment model, GLS is calculated as the change in length divided by the original length of the speckle pattern over the cardiac cycle and then is expressed as an averaged percentage from the results of each segmental peak systolic strain. Normal GLS was defined as $\leq-16 \%$, consistent with the previous literature where normal GLS is reported to range from -15.9 to $-22.1 \%[7]$.

On the other hand, as for the so-called afterload, which consists of vascular resistance, there has not been a good index. Arterial stiffness has been measured using pulse wave velocity (PWV), and a lot of useful information has been obtained as an index of vascular aging reflecting arteriosclerosis. But PWV is essentially affected by blood pressure at the time of measurement. Then, PWV could not be used for the evaluation of the effect of blood pressure on cardiac function. Recently, the cardio-ankle vascular index (CAVI) was developed as an arterial stiffness index from the origin of the aorta to the ankle $[8,9]$. The feature of CAVI is that it is independent from blood pressure (BP) at the time of measurement, because it is derived from stiffness beta theory. And it is demonstrated by the studies using $\beta 1$-blocker metoprolol and $\alpha 1$-blocker doxazosin on CAVI and BP [10]. And CAVI is proposed to reflect the socalled afterload by Shimizu et al [11] and Yamamoto et al [12]. They reported an acute change in CAVI using nitroglycerin to evaluate the vascular function in atherosclerotic patients and healthy people. Namely, CAVI is expected to be an index of vascular function for the evaluation of heart failure [13].

The relationship of LVH with CAVI was first revealed in 2015 when Schillaci et al reported that a high CAVI is associated with an inappropriately high LV mass and poor midwall systolic function by a cross-sectional survey [14].

Here, we report a woman whose LVH and GLS were improved by the combined treatment of HT, diabetes mellitus 

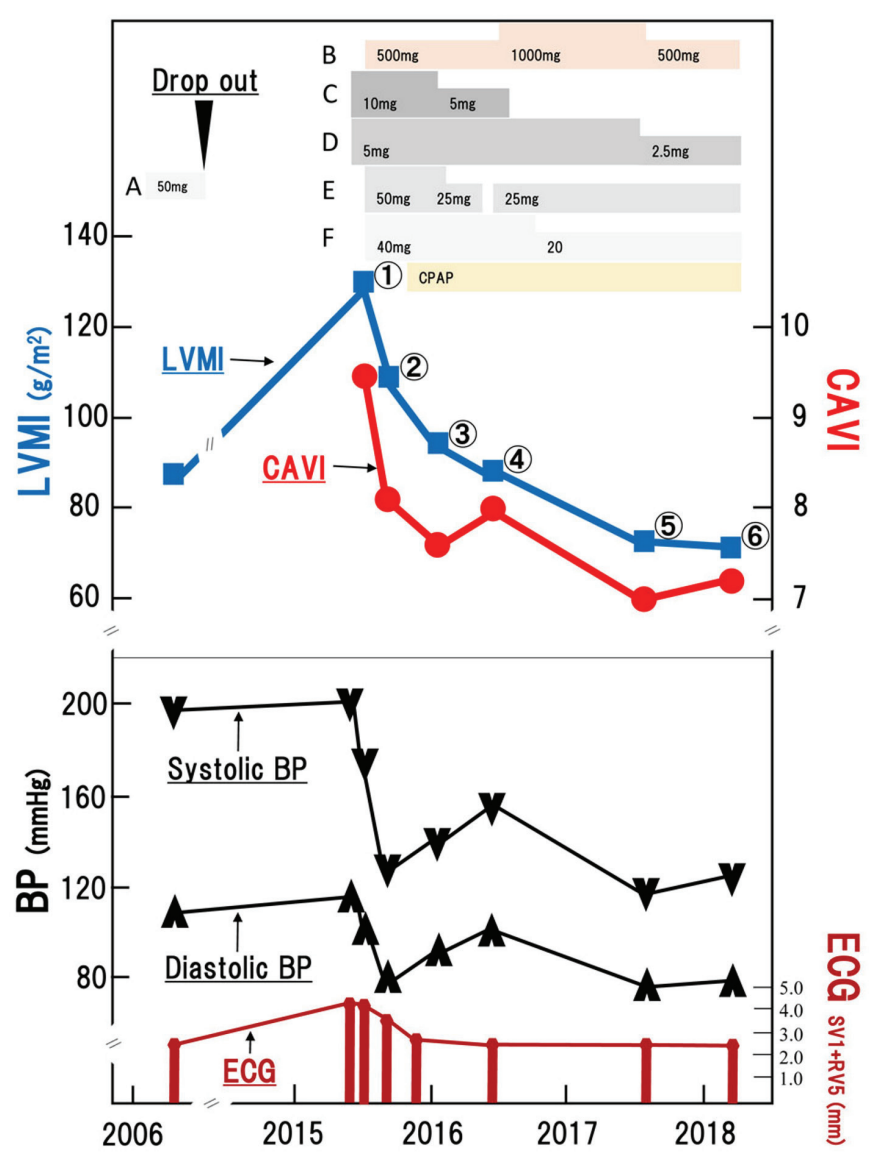

Figure 1. Clinical course of the patient. CAVI and LVMI were improved by blood pressure control and CPAP therapy for OSA. A: losartan; B: metformin; C: amlodipine; D: bisoprolol; E: spironolactone; F: telmisartan; CAVI: cardio ankle vascular index; LVMI: left ventricular mass index; BP: blood pressure; CPAP: continuous positive airway pressure; ECG: electrocardiogram.

(DM) and obstructive sleep apnea (OSA), associated with the improvement of CAVI. We tried to analyze the correlation between those LV functional indices and CAVI.

\section{Case Report}

We followed a woman in her 40s who had HT, DM, OSA and obesity. She had a past medical history of toxemia during pregnancy. Echocardiography was performed by a professional technician using Vivid S5 (General Electric Healthcare, USA) and GLS was calculated by the EchoPAC PC version 113 (General Electric Healthcare, USA) system. CAVI was measured using a Vasela 1500A (Fukuda Denshi Co., Ltd, Tokyo, Japan) in the examination room of our hospital by a professional technician. When this patient was 33 years old, she visited our hospital for the first time due to HT. However, after only a few months, she discontinued clinic visits.

All diseases were untreated for approximately a 10-year period. When she was in her early $40 \mathrm{~s}$, she was admitted to our hospital due to severe HT. On physical examination, her
BP was 207/122 mm Hg, and her pulse rate was 100 beats/ min. Heart sound and respiratory sound were clear. A chest radiogram showed that her cardiothoracic ratio was 53\%. Plasma brain natriuretic peptide (BNP) level was $151.2 \mathrm{pg} / \mathrm{mL}$. She already had advanced DM (HbAlc 10.0\%) and OSA. Her apnea hypopnea index was $28.2 \mathrm{times} / \mathrm{h}$, max apnea time was $70 \mathrm{~s}$ and minimum $\mathrm{SpO}_{2}$ was $84 \%$ in polysomnography. We did not find any endocrine abnormalities causing her HT (adrenaline $<0.01$ $\mathrm{ng} / \mathrm{mL}$, noradrenaline $0.17 \mathrm{ng} / \mathrm{mL}$, dopamine $<0.002 \mathrm{ng} / \mathrm{mL}$, cortisol $14.5 \mu \mathrm{g} / \mathrm{dL}$, plasma renin $2.3 \mathrm{ng} / \mathrm{mL} / \mathrm{h}$, and aldosterone $101 \mathrm{pg} / \mathrm{mL}$ ). Her LV geometry pattern was concentric remodeling. Her EF was preserved, and pulsed Doppler echocardiograms of the mitral inflow showed the relaxation abnormality pattern. We treated her HT, DM and OSA using various medicines and continuous positive airway pressure (CPAP). Over a few months, her BP was controlled using antihypertensive drugs and CPAP. She became a regular CPAP user and her controlled AHI level was kept within about 1.0 time/h under CPAP use. However, we failed to achieve body weight reduction. We tried to discontinue her spironolactone treatment in 2016, but her BP, serum BNP and CAVI worsened (4) in Fig. 1 and Table 1). Therefore, we continued spironolactone again.

Gradually, her condition has been improved, with improvement in LVH and GLS that is associated with the improvement of CAVI.

\section{Discussion}

Severe HT causes LVH [1]. Angiotensin II receptor blocker (ARB), spironolactone and CPAP were very effective for her BP control. Spironolactone is known to be the most effective add-on drug for the treatment of resistant HT [15]. The superiority of spironolactone supports the primary role of sodium retention. In fact, the control of her BP was affected by the discontinuation of spironolactone. On the other hand, it is known that ARB is an effective medicine for regression of LVH [16]. Miyashita et al reported that ARB was more effective than calcium antagonist for the improvement of CAVI [17]. As her LVH was improved, CAVI was also improved.

As for OSA, Kasai et al [18] and Shimizu et al [19] reported CPAP therapy which brought about improvement in CAVI. OSA is associated with increased sympathetic nerve activities and leads to resistant HT. We consider that CPAP reduces chronic activation of the sympathetic nerves caused by OSA, resulting in improvement in vascular endothelial function, and consequently a decrease in CAVI.

Most cardiovascular risk factors are associated with insulin resistance [20]. When blood glucose is well controlled in type 2 diabetes, CAVI is also improved [21, 22].

The findings from the present case suggest that improvement in CAVI caused by antihypertensive agents, antidiabetic agents and CPAP therapy may have decreased afterload of the left ventricle and accelerated the improvement of LV function. Namely, the interaction between left ventricle and vascular function as reflected by afterload was clearly demonstrated by monitoring CAVI. Furthermore, the changes in GLS were very interesting in this patient. GLS is a new method of early detection of HFpEF. Her LVEF was preserved from the begin- 
Table 1. Changes in Clinical Parameters

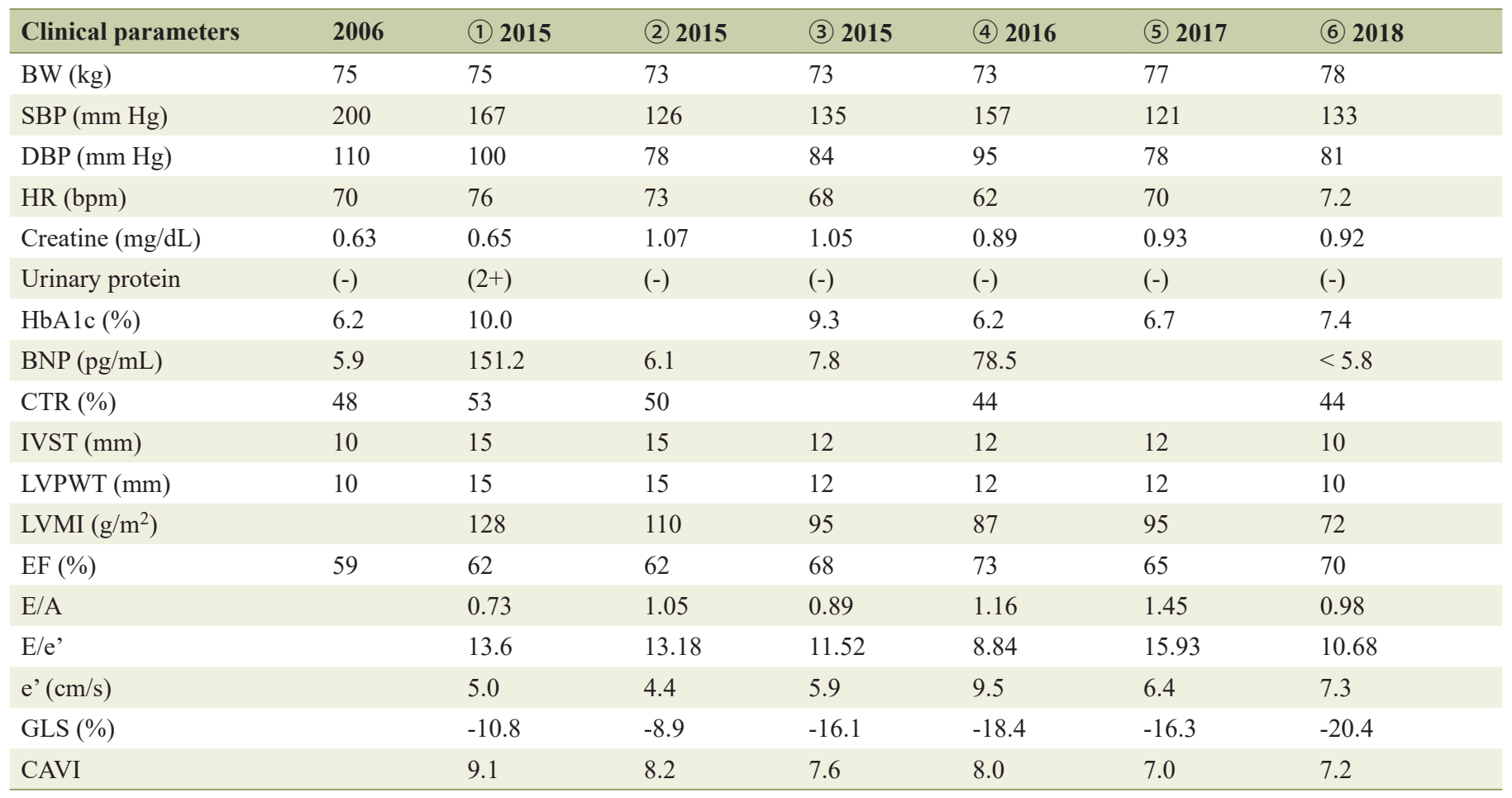

SBP: systolic blood pressure; DBP: diastolic blood pressure; HR: heart rate; bpm: beats per minute; BNP: plasma brain natriuretic peptide; CTR: cardio-thoracic ratio; IVST: interventricular septal thickness; LVPWT: left ventricular posterior wall thickness; LVMI: left ventricular mass index; EF: ejection fraction; E/A: peak early diastolic filling velocity (E-wave)/peak atrial filling velocity (A-wave); E/e': peak early diastolic filling velocity (Ewave)/spectral Doppler tissue velocities of the septal mitral annulus (e'); GLS: global longitudinal strain.

ning, as shown in Table 1. The score of GLS was gradually normalized. Especially, the LV wall became thinner and left ventricular mass index (LVMI) got lower. E/A and e' were also normalized, correlating with CAVI.

This phenomenon suggests that diastolic dysfunction of left ventricle caused by HT, DM and OSA is closely related to LVH and increased CAVI. Moreover, the findings suggest the possibility of a cardio-vascular interaction (Fig. 2), in which arterial stiffness monitored with CAVI was involved in forming cardiac hypertrophy. It had been supposed that there is a cardio-vascular interaction, but it could not be demonstrated with the index value. But, now, the presence of the interaction has been demonstrated for the first time to our knowledge by monitoring CAVI, because CAVI can reflect arterial stiffness of the arterial tree from the origin of the aorta to the ankle without the influence of blood pressure changes at the time of measurement. Although further large-scale studies are needed to prove this hypothesis, it could be suggested that the clinical process of the present case, in which the improvement of various factors reflecting CAVI led to improvement of LVH, may indicate that CAVI could be a useful index to evaluate the role of the cardio-vascular interaction in the treatment of $\mathrm{LVH}$.

\section{Conclusions}

The present case highlights the role of cardio-vascular inter- action in the treatment of concentric hypertrophy. To analyze this interaction, CAVI could be a useful index not only of the marker of atherosclerosis, but also of the vascular function in the cardio-vascular interaction.

\section{Cardio-Vascular Interaction}

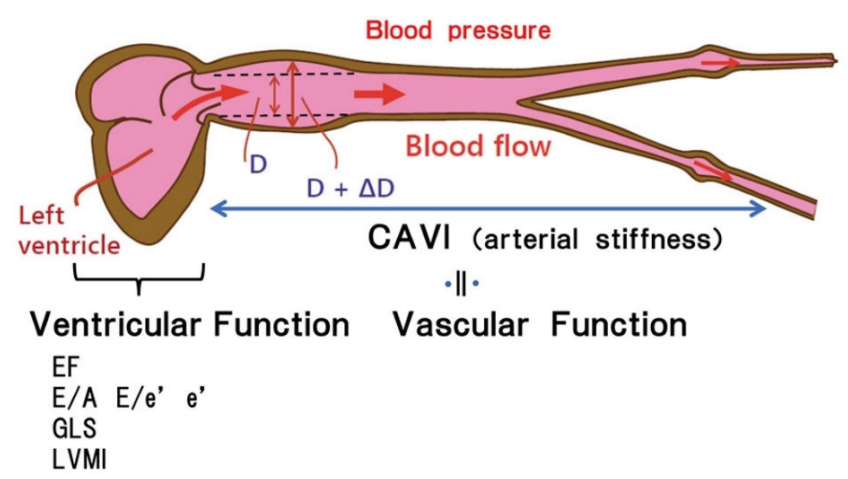

Figure 2. Cardio-vascular interaction. Vascular function was closely related with left ventricular function. CAVI: cardio ankle vascular index; E/A: peak early diastolic filling velocity (E-wave)/peak atrial filling velocity (A-wave); E/e': peak early diastolic filling velocity (E-wave)/spectral Doppler tissue velocities of the septal mitral annulus (e'); EF: ejection fraction; LVMI: left ventricular mass index; GLS: global longitudinal strain. 


\section{Ethical Statement}

All procedures were in accordance with the ethical standards of the responsible committee on human experimentation (institutional and national) and with the Helsinki Declaration of 1964 and its later versions. Informed consent was obtained from the patient for being included in this report.

\section{Conflict of Interest}

The authors report no conflict of interest in this work.

\section{Abbreviations}

LVH: left ventricular hypertrophy; HT: hypertension; EF: ejection fraction; HFpEF: preserved ejection fraction; 2D: two-dimensional; GLS: global longitudinal strain; LVEF: left ventricular ejection fraction; PWV: pulse wave velocity; CAVI: cardio-ankle vascular index; DM: diabetes mellitus; OSA: obstructive sleep apnea; BNP: brain natriuretic peptide; CPAP: continuous positive airway pressure; ARB: angiotensin II receptor blocker; LVMI: left ventricular mass index; LV: left ventricular

\section{References}

1. Dzau VJ, Antman EM, Black HR, Hayes DL, Manson JE, Plutzky J, Popma JJ, et al. The cardiovascular disease continuum validated: clinical evidence of improved patient outcomes: part I: Pathophysiology and clinical trial evidence (risk factors through stable coronary artery disease). Circulation. 2006;114(25):2850-2870.

2. Owan TE, Hodge DO, Herges RM, Jacobsen SJ, Roger VL, Redfield MM. Trends in prevalence and outcome of heart failure with preserved ejection fraction. N Engl J Med. 2006;355(3):251-259.

3. Gorcsan J, 3rd, Tanaka H. Echocardiographic assessment of myocardial strain. J Am Coll Cardiol. 2011;58(14):14011413.

4. Butler J, Fonarow GC, Zile MR, Lam CS, Roessig L, Schelbert EB, Shah SJ, et al. Developing therapies for heart failure with preserved ejection fraction: current state and future directions. JACC Heart Fail. 2014;2(2):97-112.

5. Mignot A, Donal E, Zaroui A, Reant P, Salem A, Hamon C, Monzy S, et al. Global longitudinal strain as a major predictor of cardiac events in patients with depressed left ventricular function: a multicenter study. J Am Soc Echocardiogr. 2010;23(10):1019-1024.

6. Buss SJ, Emami M, Mereles D, Korosoglou G, Kristen AV, Voss A, Schellberg D, et al. Longitudinal left ventricular function for prediction of survival in systemic light-chain amyloidosis: incremental value compared with clinical and biochemical markers. J Am Coll Cardiol. 2012;60(12):1067-1076.

7. Yingchoncharoen T, Agarwal S, Popovic ZB, Marwick
TH. Normal ranges of left ventricular strain: a meta-analysis. J Am Soc Echocardiogr. 2013;26(2):185-191.

8. Shirai K, Utino J, Otsuka K, Takata M. A novel blood pressure-independent arterial wall stiffness parameter; cardio-ankle vascular index (CAVI). J Atheroscler Thromb. 2006;13(2):101-107.

9. Hayashi K, Yamamoto T, Takahara A, Shirai K. Clinical assessment of arterial stiffness with cardio-ankle vascular index: theory and applications. J Hypertens. 2015;33(9):1742-1757; discussion 1757.

10. Shirai K, Song M, Suzuki J, Kurosu T, Oyama T, Nagayama D, Miyashita Y, et al. Contradictory effects of beta1and alpha1- aderenergic receptor blockers on cardio-ankle vascular stiffness index (CAVI) - CAVI independent of blood pressure. J Atheroscler Thromb. 2011;18(1):4955 .

11. Shimizu K, Yamamoto T, Takahashi M, Sato S, Noike $\mathrm{H}$, Shirai K. Effect of nitroglycerin administration on cardio-ankle vascular index. Vasc Health Risk Manag. 2016;12:313-319.

12. Yamamoto T, Shimizu K, Takahashi M, Tatsuno I, Shirai K. The Effect of Nitroglycerin on Arterial Stiffness of the Aorta and the Femoral-Tibial Arteries. J Atheroscler Thromb. 2017;24(10):1048-1057.

13. Zhang C, Ohira M, Iizuka T, Mikamo H, Nakagami T, Suzuki M, Hirano K, et al. Cardio-ankle vascular index relates to left ventricular ejection fraction in patients with heart failure. A retrospective study. Int Heart J. 2013;54(4):216-221.

14. Schillaci G, Battista F, Settimi L, Anastasio F, Pucci G. Cardio-ankle vascular index and subclinical heart disease. Hypertens Res. 2015;38(1):68-73.

15. Williams B, MacDonald TM, Morant S, Webb DJ, Sever P, McInnes G, Ford I, et al. Spironolactone versus placebo, bisoprolol, and doxazosin to determine the optimal treatment for drug-resistant hypertension (PATHWAY-2): a randomised, double-blind, crossover trial. Lancet. 2015;386(10008):2059-2068.

16. Okin PM, Devereux RB, Harris KE, Jern S, Kjeldsen SE, Lindholm LH, Dahlof B, et al. In-treatment resolution or absence of electrocardiographic left ventricular hypertrophy is associated with decreased incidence of new-onset diabetes mellitus in hypertensive patients: the Losartan Intervention for Endpoint Reduction in Hypertension (LIFE) Study. Hypertension. 2007;50(5):984-990.

17. Miyashita Y, Saiki A, Endo K, Ban N, Yamaguchi T, Kawana H, Nagayama D, et al. Effects of olmesartan, an angiotensin II receptor blocker, and amlodipine, a calcium channel blocker, on Cardio-Ankle Vascular Index (CAVI) in type 2 diabetic patients with hypertension. J Atheroscler Thromb. 2009;16(5):621-626.

18. Kasai T, Inoue K, Kumagai T, Kato M, Kawana F, Sagara $\mathrm{M}$, Ishiwata $\mathrm{S}$, et al. Plasma pentraxin3 and arterial stiffness in men with obstructive sleep apnea. Am J Hypertens. 2011;24(4):401-407.

19. Shimizu K, Yamamoto T, Shirai K. Arterial stiffness, as monitored by cardio-ankle vascular index, is affected by obstructive sleep apnea, blood glucose control, and body weight - a case with 8 years follow up. Int Med Case 
Rep J. 2016;9:231-235.

20. Scarpello JH, Howlett HC. Metformin therapy and clinical uses. Diab Vasc Dis Res. 2008;5(3):157-167.

21. Ohira M, Yamaguchi T, Saiki A, Ban N, Kawana H, Nagumo A, Murano T, et al. Pioglitazone improves the cardio-ankle vascular index in patients with type 2 diabetes mellitus treated with metformin. Diabetes Metab Syndr Obes. 2014;7:313-319.

22. Nagayama D, Saiki A, Endo K, Yamaguchi T, Ban N, Kawana H, Ohira M, et al. Improvement of cardio-ankle vascular index by glimepiride in type 2 diabetic patients. Int J Clin Pract. 2010;64(13):1796-1801. 